\title{
FORMULAE DERIVED FROM ANTHROPOMETRIC MEASUREMENTS TO ESTIMATE IDEAL TIBIAL NAIL LENGTH
}

\author{
FÓRMULAS DERIVADAS DE MEDIDAS ANTROPOMÉTRICAS PARA \\ ESTIMATIVA DO COMPRIMENTO IDEAL DA HASTE TIBIAL
}

\author{
Cem AlbaY ${ }^{1}$ (1), Mehmet AKIF KayGusuz ${ }^{1}$ (i) \\ 1. Metin Sabanci Baltalimani Bone Disease Research and Training Hospital, Department of Orthopaedics and Traumatology, Istanbul, Turkey.
}

\section{ABSTRACT}

Introduction: Ideal Nail Length (INL) provides better outcomes after Intramedullary Nailing (IMN) of Tibia Shaft Fractures (TSF). Intraoperative methods do not allow for preoperative planning. Changing the nail may cause complications. X-rays are commonly used, but displacement or magnification errors may occur. Forearm measurements may be benefical in bilateral TSF. We aim to examine correlations of anthropometric measurements (AMs) and INL and use them to obtain formulae. Materials and methods: Tuberositas Tibia-Medial Malleolus (TM), Tuberositas Tibia-Ankle joint (TA), knee-ankle joint (JJ), and olecranon tip-5th Metacarpal head (OM) distances were evaluated in 76 IMN patients. Correlation analyses were performed and the results used to create formulae. Results: The correlations between INL and TM-left, TM-right, TA-left, TA-right, OM-left, OM-right, JJ-left, JJ-right were $0.81,0.83,0.77,0.77$, $0.82,0.80,0.90,0.91$ respectively for males; and $0.93,0.89$, $0.88,0.86,0.80,0.82,0.90,0.89$ respectively for females. AMs show excellent correlation in both sexes $(p<0.0001)$. Regression analysis was statistically significant in all formulae. The most compatible correlations in males were $\mathrm{JJ}$-right and $\mathrm{JJ}$-left; and in females, TM-left, TM-right, and JJ-right. Conclusion: The most compatible correlations wth INL were $\mathrm{JJ}$ in males, and TM and $\mathrm{JJ}$ in females. OM can be used in the presence of bilateral TSF, edema, wounds and obesity. AMs are useful preoperatively. The formulae can be used to ensure INL and reduce errors, time and radiation. Level of Evidence: Level I, Testing of previously developed diagnostic criteria on consecutive patients (with the universally applied reference gold standard).

Keywords: Tibial fractures, Intramedullary nailing, Anthropometry.

\section{RESUMO}

Introdução: O comprimento ideal da haste $(\mathrm{ClH})$ proporciona desfechos melhores depois da colocação de haste intramedular (HIM) em fraturas da diáfise da tíbia (FDT). Os métodos dessa cirurgia não permitem o planejamento pré-operatório. A troca da haste pode causar complicações. Em geral, são usadas radiografias, mas podem ocorrer erros de deslocamento ou de tamanho. As medições do antebraço podem ser benéficas nas FDTs bilaterais. Nosso objetivo é examinar as correlações das medidas antropométricas (MAs) e ClH e usá-las para obter fórmulas. Materiais e métodos: As distâncias entre Tuberosidade da tíbia-Maléolo medial (TM), Tuberosidade da tíbia-Articulação do tornozelo (TT), Articulações do joelho e do tornozelo (JT) e extremidade do olécrano-cabeça do $5^{\circ}$ metacarpal (OM) foram avaliadas em 76 pacientes com HIM. Foram realizadas análises de correlação e os resultados foram usados para criar fórmulas. Resultados: As correlações entre $\mathrm{ClH}$ e TM-esquerda, TM-direita, TT-esquerda, TT-direita, OM-esquerda, OM-direita, JT-esquerda, JT-direito foram 0,81, 0,83, 0,77, 0,77, 0,82, 0,80, 0,90, 0,91 para homens e 0,93, 0,89, 0,88, 0,86, 0,80, 0,82, 0,90, 0,89 para mulheres. As MAs tiveram excelente correlação em ambos os sexos $(p<0,0001)$. A análise de regressão foi estatisticamente significativa em todas as fórmulas. As correlações mais compatíveis em homens foram JT-direita e JT-esquerda; nas mulheres, foram TM-esquerda, TM-direita, e JT-direita. Conclusão: As correlações mais compatíveis com CIH foram JT em homens e TM e JT em mulheres. A OM pode ser usada em FDT bilateral, edema, feridas e obesidade. As MAs são úteis no pré-operatório. As fórmulas podem ser usadas para garantir o ClH e reduzir erros, tempo e radiação. Nível de evidência: Nível I, Desenvolvimento de critérios diagnósticos em pacientes consecutivos (com padrão de referência "ouro" aplicado).

Descritores: Fraturas da tíbia, Haste intramedular, Antropometria.

Citation: Albay C, Kaygusuz MA. Formulae derived from anthropometric measurements to estimate ideal tibial nail length. Acta Ortop Bras. [online]. 2021;29(2):7661-5. Available from URL: http://www.scielo.br/aob.

All authors declare no potential conflict of interest related to this article.

The study was conduced at Metin Sabanci Baltalimani Bone Disease Research and Training Hospital.

Correspondence: Baltalimanı, Balta Limanı Hisar Cd. 62, 34470 Sarıyer/Istanbul, Turkey. cemalbay@hotmail.com

Article received on 09/30/2020, approved on 01/21/2021. 


\section{INTRODUCTION}

Tibia shaft fracture (TSF) is the most common long bone fracture with an incidence of 16.9/100.000 per year. ${ }^{1}$ Intramedullary nailing (IMN); is the gold standard and most used treatment option for adult TSF. ${ }^{2}$ Better outcomes after IMN of TSFs can be achieved by ensuring anatomical reduction and choosing the correct nail length $(\mathrm{NL}){ }^{3}$ IMN between $0.5-1 \mathrm{~cm}$ distal to knee joint and $1-2 \mathrm{~cm}$ proximal to ankle is recommended as Ideal Nail Length (INL) in literature. ${ }^{4-6}$ Intraoperative measurements can be made by guidewire method and surgical ruler. ${ }^{3}$ On the other hand, these methods do not allow preoperative planning, as a result they may cause prolonged anesthesia and operation time, associated infection and bleeding, and extra radiation exposure of the patient and surgical team. Changing the improper NL during surgery may prolong the duration of surgery and anesthesia and may cause additional complications associated with it. If all NLs are not available for surgery, inappropriate nail placement may be encountered. Therefore, careful preoperative planning is essential for TSF like any orthopedic surgical procedure. Radiographic measurements can be used for preoperative planning. Preoperative radiographic measurement of broken or contralateral tibia can be used but problems due to displacement of fracture or magnification errors may occur. Various anthropometric methods have been used to calculate the appropriate NL in tibia IMN surgery. Although height of the patient was used for this purpose, it is not accepted for tibial nail as a sufficient value alone. , $^{3}$ Distance between Tuberositas Tibia and Medial Malleol (TM), distance between Tuberositas Tibia and Ankle joint (TA), distance between knee joint line and ankle joint line $(\mathrm{JJ})$ were evaluated. In the presence of bilateral tibia fractures, obesity and wounds on tibia; the distance between the olecranon tip point and the 5th Metacarpal head level (OM) was evaluated for preoperative planning of NL. Evaluating these measurements together is important in the presence of multitrauma in particular. However, there are very few studies in the literature where the distances of TM, TA, OM, JJ are used for tibial measurement. Unfortunately, in these studies; cadavers and healthy volunteers were used to examine the consistency of anthropometric measurements (AM) instead of patients suffering from TSF, and the correlations of these AM are leaking in the literature for real TSF patients. Also the present studies do not present a formula to orthopaedic surgeons to reach NL.

In the current study; we aim to examine correlations of AMs with NL, and we aim to obtain formulas to place the ideal nail for TSF to guide orthopaedic surgeons.

\section{MATERIALS AND METHODS}

Patients with TSFs treated with IMN between 2015 and 2020 were retrospectively screened. 216 patients who had unilateral IMN, who did not develop fractures on the contralateral tibia and forearm were invited to our hospital by phone. 92 of the invited patients admitted to the hospital. Informed consent was taken from all subjects. The current study was approved by the local ethic committee of hospital with 59/427 decision/protocol number. Patients with a Body mass index (BMI) between 25 and 30 were included to avoid landmark palpation difficulties of obese patients. Patients with another history of trauma to the lower limbs and forearm, patients with soft tissue injuries on the measurement side such as burns that caused scar formation, and patients with limb inequality were excluded from the study to avoid patient's trauma related measurement errors.

As a result of the radiographic evaluation by tibia AP X-ray, the NLs of the patients were evaluated. A radiographic ruler was used and X-ray with $\% 100$ magnification from 1 meter distance were taken, and nails terminated $1 \mathrm{~cm}$ proximal to the ankle joint and $1 \mathrm{~cm}$ below the knee joint were evaluated as INL in guide of literatüre. ${ }^{3-6}$ As a result, a total of 76 patients with INL of whom 61 were males and 15 were females were included in the study. TM, TA, OM, JJ of both sides of 76 patients who participated in our study were measured and recorded with their demographic characteristics and fracture sides. TM was measured from the most prominent point on tuberositas tibia to the most prominent point on medial malleolus. ${ }^{3-4}$ (Figure 1) TA was measured from the most prominent point on tuberositas tibia to the distal rim of the tibial plafond. ${ }^{7}$ (Figure 2) OM was measured as a distance between the olecranon tip to the 5th metacarpal head when the elbow and metacarpophalangeal joints were in 90 degrees of flexexion and wrist was neutral. ${ }^{6}$ (Figure 3) $\mathrm{JJ}$ was measured as a distance between the point $3 \mathrm{~cm}$ medial to patellar tendon's medial edge to tibial plafond's distal rim which is felt as a joint depression at the medial corner ${ }^{3-7}$ (Figure 4) This measurement is performed when the knee is flexed, the ankle is dorsiflexed and the leg is in external rotation ${ }^{5}$ All measurements were made by authors twice with the same tape measure and average of the values were taken. In our study, the relationship between TM, TA, OM, JJ values and INL was determined. For preoperative planning, it was aimed to reach INL through AM by creating a formula according to the AM values of male and female genders.

Ethics committee approval was received for this study from the Ethics Committee of the hospital (59/427). The authors certify that they have obtained all appropriate patient consent forms. In the form, the patient(s) has/have given his/her/their consent for his/her/their images and other clinical information to be reported in the journal.

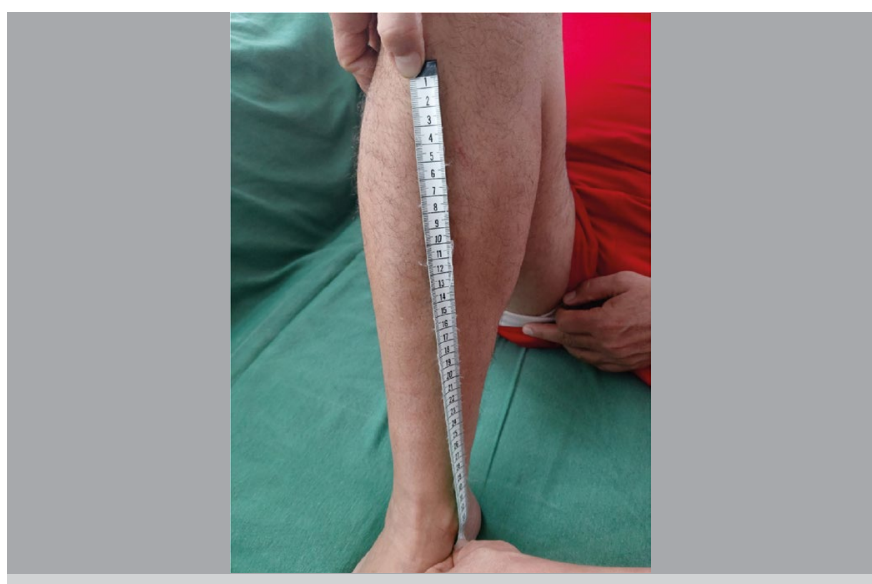

Figure 1. Tuberositas Tibia and Medial Malleol Distance (TM).

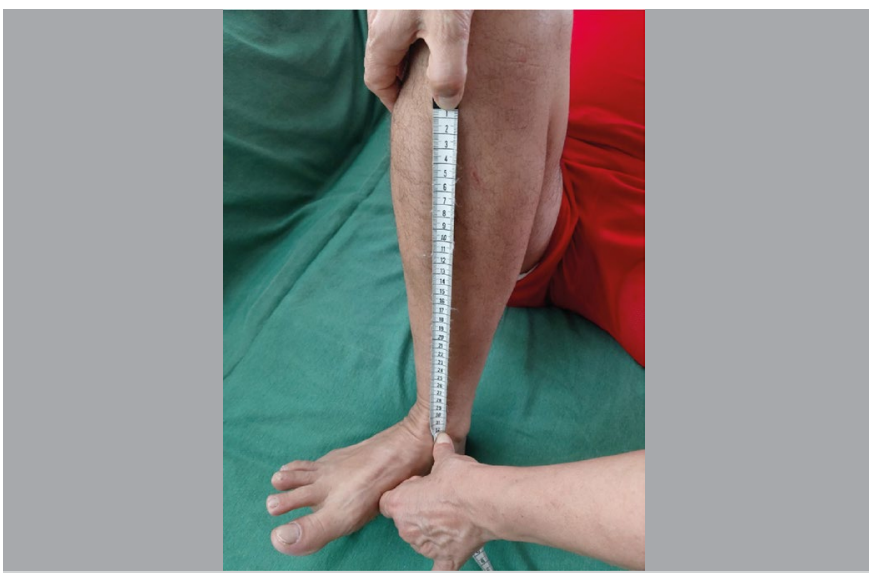

Figure 2. Tuberositas Tibia and Ankle joint (TA) Distance. 


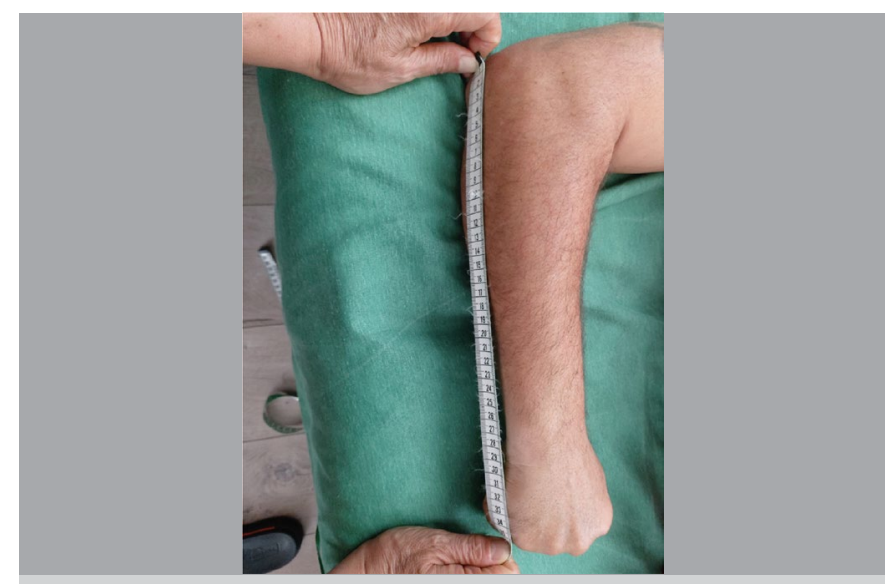

Figure 3. Olecranon Tip and 5th Metacarpal Head (OM) distance.

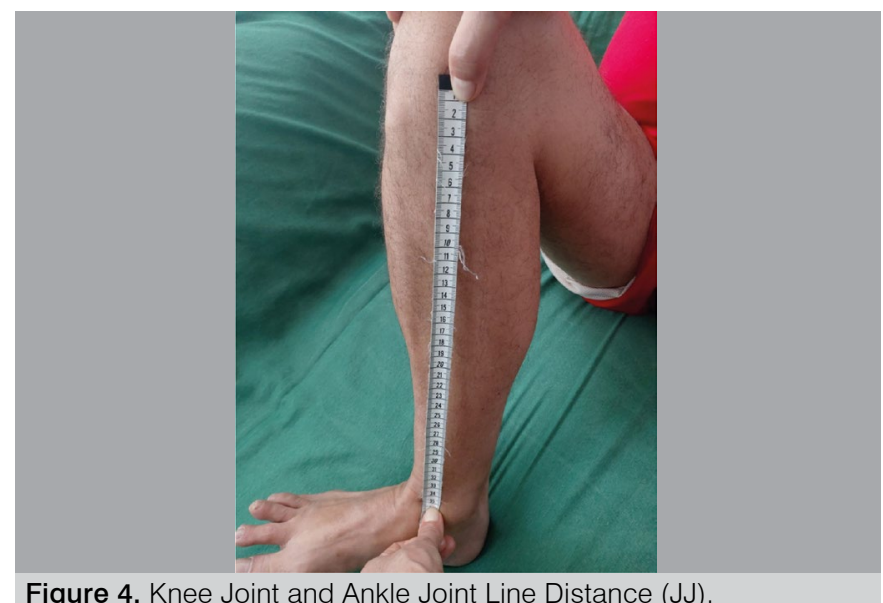

\section{Statistical Analysis}

Statistical analysis was performed using SPSS version 22 Chicago: SPSS Inc. Kolmogorov-Smirnov and Shapiro Wilk tests were performed for the evalution of normality. A Student's t-test and Mann Whitney $U$ test were used for the comparison of continuous variables between the groups. Non-parametric Spearman's correlation coefficiency and and Pearson's correlation tests were applied for the correlation analysis of the data. Linear regression analysis was performed for the assessment of evaluation between the AMs and INL $(95 \% \mathrm{Cl})$.

\section{RESULTS}

There were 76 patients in the study of whom 15 were female and 61 were male. 9 females and 30 males had left side and, 6 females and 31 males had right side fracture. 39 patients had left tibia IMN and 37 patients had right tibia IMN. There was no statistically significant difference in terms of fracture side $(p=0.568)$. Comparison of the demographic features and AMs of extremities in patient groups are presented in Table 1. All mean AM values and mean NL of male patients were longer than female patients.

Correlation values of left and right TM, TA, OM, JJ values of male patients and NL are presented in Table 2. Correlations between NL of the male patients and TM left, TM right, TA left, TA right, OM left, OM right, JJ left and JJ right were 0.81, 0.83, 0.77, 0.77, 0.82, 0.80, $0.90,0.91$ respectively. According to Table 2, TM, TA, OM, JJ and NL show high correlation in male patients $(p<0.0001)$.

Correlation analysis of TM, TA, OM, JJ values of female patients with each other and $\mathrm{NL}$ is presented in table 2. Correlations between NL of the female patients and TM left, TM right, TA left, TA right, OM left, OM right, JJ left and $\mathrm{JJ}$ right were $0.93,0.89,0.88,0.86,0.80,0.82$, $0.90,0.89$ respectively. According to Table $2, \mathrm{TM}, \mathrm{TA}, \mathrm{OM}, \mathrm{JJ}$ and $\mathrm{NL}$ values of female patients showed high correlation $(p<0.0001)$. The anthropometric values of the patients and INL were analyzed and the formulas were obtained for preoperative planning. Accordingly, formulas that can be used in male patients are presented in Table 3. Regression analysis was statistically significant in the formulas of male patients $(p<0.0001)$. JJ Right $\left(R^{2}=0.8284\right)$ and JJ Left $\left(R^{2}=0.8091\right)$ values were determined as the most compatible results. (Table 3) The formulas obtained by analyzing the INL through the AM of female patients are presented in Table 4. Regression analysis was statistically significant in the formulas of female patients (TM left, TM right, TA left TA right, and JJ right ( $p<0.0001)$; OM left, $\mathrm{OM}$ right, JJ left $(\mathrm{p}<0.001)$ ). (Table 4$)$ In female patients, TM left $\left(R^{2}=0.8735\right)$, TM right $\left(R^{2}=0.8069\right)$, JJ right $\left(R^{2}=0.8023\right)$ gave the most compatible result, respectively.

Table 1. Comparison of the anthropometric measurements (in $\mathrm{cm}$ ) of the extremities in patient groups.

\begin{tabular}{c|c|c|c|c}
\hline & Mean SD & $\begin{array}{c}\text { Female }(\mathbf{n}=15) \\
\text { Mean } \pm \text { SD }\end{array}$ & $\begin{array}{c}\text { Male }(\mathbf{n}=61) \\
\text { Mean } \pm \text { SD }\end{array}$ & p value \\
\hline Age & $39.38 \pm 13.33$ & $40.27 \pm 12.27$ & $39.16 \pm 13.66$ & 0.776 \\
\hline L/R & $39 / 37$ & $9 / 6$ & $30 / 31$ & 0.568 \\
\hline TM Left & $33.40 \pm 2.00$ & $31.67 \pm 1.51$ & $33.82 \pm 1.88$ & $<0.0001$ \\
\hline TM Right & $33.44 \pm 2.08$ & $31.69 \pm 1.75$ & $33.87 \pm 1.94$ & $<0.0001$ \\
\hline TA Left & $31.71 \pm 2.10$ & $30.31 \pm 1.86$ & $32.05 \pm 2.03$ & $<0.01$ \\
\hline TA Right & $31.75 \pm 2.15$ & $30.27 \pm 1.92$ & $32.11 \pm 2.05$ & $<0.01$ \\
\hline OM Left & $34.43 \pm 2.22$ & $31.94 \pm 2.22$ & $35.05 \pm 1.75$ & $<0.0001$ \\
\hline OM Right & $34.52 \pm 2.15$ & $32.00 \pm 2.17$ & $35.14 \pm 1.65$ & $<0.0001$ \\
\hline JJ Left & $34.72 \pm 2.53$ & $32.47 \pm 2.11$ & $35.28 \pm 2.32$ & $<0.0001$ \\
\hline JJ Right & $34.73 \pm 2.59$ & $32.40 \pm 2.19$ & $35.3 \pm 2.37$ & $<0.0001$ \\
\hline Nail length & $32.11 \pm 2.35$ & $29.73 \pm 1.98$ & $32.69 \pm 2.06$ & $<0.0001$ \\
\hline
\end{tabular}

Table 2. Correlation for Nail Length of Males and Females with Anthropometric measurements.

\begin{tabular}{c|c|c|c|c|c|c|c|c}
\hline & TM Left & TM Right & TA Left & TA Right & OM Left & OM Right & JJ Left & JJ Right \\
\hline $\begin{array}{c}\text { NL of } \\
\text { Males }\end{array}$ & $0.81^{*}$ & $0.83^{*}$ & $0.77^{*}$ & $0.77^{*}$ & $0.82^{*}$ & $0.80^{*}$ & $0.90^{*}$ & $0.91^{*}$ \\
\hline $\begin{array}{c}\text { NL of } \\
\text { females }\end{array}$ & $0.93^{*}$ & $0.89^{*}$ & $0.88^{*}$ & $0.86^{*}$ & $0.80^{*}$ & $0.82^{*}$ & $0.90^{*}$ & $0.89^{*}$ \\
\hline
\end{tabular}

TM: Tuberositas tibia-Medial malleol distance, TA: Tuberositas tibia-Ankle Joint distance, OM: Olecranon tip-5th Metacarpal Head Distance, JJ: Knee - Ankle Joint distance, NL: Nail Length, ${ }^{*} p<0.0001$

Table 3. Regression equations for male subjects according to Antropometric measurements.

\begin{tabular}{c|c|c|c}
\hline mease $(\mathbf{n}=61)$ & Formula & $\mathbf{R}^{2}$ & $\mathbf{p}$ \\
\hline TM Left & $=0.7416^{\star} \mathrm{X}+9.583( \pm 2.272)$ & 0.6595 & $\mathrm{p}<0.0001$ \\
\hline TM Right & $=0.7832^{\star} \mathrm{X}+8.266( \pm 2.223)$ & 0.6930 & $\mathrm{p}<0.0001$ \\
\hline TA Left & $=0.7605^{\star} \mathrm{X}+7.192( \pm 2.678)$ & 0.5945 & $\mathrm{p}<0.0001$ \\
\hline TA Right & $=0.7722^{\star} \mathrm{X}+6.866( \pm 2.695)$ & 0.5989 & $\mathrm{p}<0.0001$ \\
\hline OM Left & $=0.7065^{\star} \mathrm{X}+11.95( \pm 2.039)$ & 0.6857 & $\mathrm{p}<0.0001$ \\
\hline OM Right & $=0.6435^{\star} \mathrm{X}+14.10( \pm 2.034)$ & 0.6455 & $\mathrm{p}<0.0001$ \\
\hline JJ Left & $=1.015^{\star} \mathrm{X}+2.106( \pm 2.102)$ & 0.8091 & $\mathrm{p}<0.0001$ \\
\hline JJ Right & $=1.047^{\star} \mathrm{X}+1.074( \pm 2.032)$ & 0.8284 & $\mathrm{p}<0.0001$ \\
\hline
\end{tabular}

TM: Tuberositas tibia-Medial malleol distance, TA: Tuberositas tibia-Ankle Joint distance, OM Olecranon tip-5th Metacarpal Head Distance, JJ: Knee-Ankle Joint distance, X=Ideal Nail Length 
Table 4. Regression equations for female subjects according to Antropometric measurements.

\begin{tabular}{c|c|c|c}
\hline FEMALE $(\mathbf{n}=15)$ & Formula & $\mathbf{R}^{2}$ & $\mathbf{p}$ \\
\hline TM Left & $=0.7148^{\star} X+10.41( \pm 2.248)$ & 0.8735 & $\mathrm{p}<0.0001$ \\
\hline TM Right & $=0.7968^{\star} X+8.000( \pm 3.222)$ & 0.8069 & $\mathrm{p}<0.0001$ \\
\hline TA Left & $=0.8311^{\star} X+5.603( \pm 3.653)$ & 0.7794 & $\mathrm{p}<0.0001$ \\
\hline TA Right & $=0.8422^{\star} X+5.224( \pm 4.039)$ & 0.7480 & $\mathrm{p}<0.0001$ \\
\hline OM Left & $=0.9095^{\star} X+4.899( \pm 5.478)$ & 0.6531 & $\mathrm{p}<0.001$ \\
\hline OM Right & $=0.8993^{\star} \mathrm{X}+5.262( \pm 5.212)$ & 0.6702 & $\mathrm{p}<0.001$ \\
\hline JJ Left & $=0.8791^{\star} \mathrm{X}+6.334( \pm 4.990)$ & 0.6794 & $\mathrm{p}<0.001$ \\
\hline JJ Right & $=0.9939^{\star} \mathrm{X}+2.847( \pm 4.077)$ & 0.8023 & $\mathrm{p}<0.0001$
\end{tabular}

TM: Tuberositas tibia-Medial malleol distance, TA: Tuberositas tibia-Ankle Joint distance, OM

Olecranon tip-5th Metacarpal Head Distance, JJ: Knee-Ankle Joint distance, X=Ideal Nail Length

\section{DISCUSSION}

Anatomical reduction of TSF and ensuring stability with the INL is very important in terms of recovery of the functions. It increases the quality of life, enables to return to social life and work earlier, and it requires meticulous preoperative planning. Proper NL is essential for surgical success. ${ }^{3}$ Nails shorter than they should be can result in malrotation, loss of reduction and fixation failure. Extraction of the nail can not be performed when necessary, if nail is too short. NL longer than it should be can distract the fracture site and can result ankle and/or knee joint penetration and patellar tendon impingement. In this sense, NL should start from $0.5-1 \mathrm{~cm}$ distal to the knee joint and extend to $1-2 \mathrm{~cm}$ proximal to the ankle. ${ }^{4,8}$ In our study, we evaluated the nail length starting from $1 \mathrm{~cm}$ distal of the knee joint to $1 \mathrm{~cm}$ proximal to the ankle joint as the INL.

In the surgery of TSF, all nail sizes should be kept ready in the operating room. Intraoperative guide wire method and radiographic ruler can be used. ${ }^{3}$ However, these intraoperative methods do not allow preoperative planning. In cases of emergency conditions, when the appropriate nail is not ready in the operating room, the application of the non-ideal NL to the patient may be faced. Therefore, the surgeon must ensure that the correct NLs are ready by making appropriate preoperative planning

Intraoperative errors, anesthesia and operative time and radiation exposure of surgical team and patient are reduced by proper preoperative nail planning ${ }^{3-7}$ For this reason, radiographic measurements and $\mathrm{AM}$ can be used for preoperative planning such as radiographic templates and patient height. . $^{9-11}$

Preoperative radiographic measurement of broken or contralateral tibia can be used. However, the correct length may not be accurately measured due to translation and displacement of broken fragments. Moreover, the magnification of the radiographs does not always reflect the actual length.

It should be taken into consideration that the radiographs of the contralateral tibia may not be taken with equal magnification at an equal distance to each trauma patient under emergency conditions. Splinting and leg positioning may also affect the magnification. The presence of leg length inequalities, past TSF or lower limb deformities limit the use of broken and contralateral tibia to calculate NL. ${ }^{6}$ Using patient height in preoperative planning is not recommended due to low accuracy. ${ }^{3-7}$ Since the soft tissue coverage of the tibia is relatively less, it is suitable for various anthropometric methods based on bone and joint landmarks. Therefore; JJ, TM, TA were evaluated preoperatively to have the correct NL ready in the operating room. However, due to the reasons such as obesity, density of subcutaneous fatty tissue, the presence of wounds and lesions on landmarks, fracture of the contralateral tibia, and inability to perform appropriate measurements due to edema of crus pushed orthopedic surgeons to search for landmarks from other parts of the body. ${ }^{6,12}$ For these reasons, the $\mathrm{OM}$, in which bone landmarks are easily determined, was used.

Studies using these AM in the literature have obtained variable results in calculating the possible NL. For example, while Venkateswaran et al found 64\% accuracy with TM; Colen and Prieskorn stated that TM distance is the most compatible measurement with $71 \%$ accuracy $(4,5)$. In contrast, Galbraith et al suggested using the $\mathrm{JJ}$ distance for calculating the NL (3). Isaac et al added $11 \mathrm{~mm}$ to the TA distance and found the highest correlation with the nail length with $81 \%$, and suggested to use the TA distance in preoperative planning. ${ }^{7}$ Venkateswaran et al reported that the subtracting $20 \mathrm{~mm}$ from the $\mathrm{JJ}$ distance showed the highest accuracy with $86 \% .^{5}$

These studies were mostly performed on healthy volunteers and present the AM values of healthy people. In these studies on volunteers, the correlations of AM with each other were evaluated; it is not based on radiographic measurements. The number of cadaver studies using radiographic measurements is limited. In our study, the actual NL was calculated by radiography in real magnification, so there was no need for computed tomography. The average age of the cadaver studies does not meet the age group in which TSFs are common. In addition, AMs made on cadavers may show differences due to positioning differences, palpation differences due to the absence of sense of pain during measurement, and the lack of landmarks due to subcutaneous fatty tissue and atrophy of muscle tissue. Our study is based on AMs of real patients who underwent IMN surgery due to TSF; evaluates the correlation of these values with the INL.

Studies in the literature have made investigations for the calculation of NL by adding or subtracting a fixed value to AM. According to our study, the mean NL varies depending on the gender. In addition, keeping the added or subtracted value constant may increase the margin of error according to the size of the measured anthropometric value. For this reason, creating a formula instead of a constant value can increase the possibility of obtaining the INL.

Depending on the reasons such as wound in the measurement area, presence of trauma-related edema, patient's inability to tolerate manipulations related to fracture pain; one or more of the measured anthropometric values may not be used. Therefore, in our study, we obtained formulas by evaluating the correlations by making all AM from both the right and left sides. In this way, we also ensured the sustainability of preoperative planning in multitrauma patients. According to our study, AM of the right and the left extremities showed high correlation with INL and are presented in Table 2. In the current study, the highest correlation between AM and NL in male patients was found with JJ similar to Galbraith and Venkateswaran. ${ }^{6,11}$ In male patients, TM, OM, and TA followed JJ respectively.

The highest correlation between AM and NL was found in TM and $\mathrm{JJ}$, followed by TA and OM in female patients. Our study also stated that AM can be used as Isaac, Venkateswaran, Colen and Prieskorn indicated. 3,11 In addition, the current study showed that OM can be used with high correlation in cases with bilateral tibia fracture, obesity, skin wounds and lesions, burn scars and edema as Blair stated. ${ }^{2}$ Moreover, our study has provided formulas for real TSF patients treated with INL and unlike other studies, the highest compatible AM that can be recommended by sex are separated.

Accordingly, it has been shown that $\mathrm{JJ}$ accuracy is higher in male patients, and TM and $\mathrm{JJ}$ accuracies are higher in female patients. We recommend to evaluate AMs simultaneously and to have the INL ready in the operating room before starting the surgery.

In this sense, the current study is the first study aiming to reach the INL by formulas according to the female and male sexes separately and the broken side. Our study includes a high number of cases compared to other studies. However, the number of female patients is relatively less. 
The limitation of the current study is the lower case numbers of female patients especially for left side fractures. This study was performed in a single center and gives information of a single race. It may be a guide for multicentric studies in which especially the number of female patients is increased.

\section{CONCLUSION}

In our study, the correlation between INL and AM according to the fracture side in male and female patients was examined; found greater compatibility with $\mathrm{J} \mathrm{J}$ in male patients and TM and $\mathrm{J} \mathrm{J}$ in female patients. The formulas presented by our study in the preoperative evaluation may ensure that INL is available in the operating room and can prevent the operation from starting without having the appropriate NL. By shortening the duration of surgery and anesthesia with preoperative planning, it may reduce associated blood loss, infection risk and radiation dose. Our study is guiding surgeons for multitrauma patients because it contains different AMs. It can be used in preoperative planning as a fast, easy-to-apply method without financial burden.

AUTHORS' CONTRIBUTIONS: Each author made significant individual contributions to the development of this manuscript. Albay C: writing, literature search, anthropometric measurements and data analysis; Kaygusuz MA: anthropometric measurements, review of the article and intellectual concept of the article.

\section{REFERENCES}

1. Anandasivam NS, Russo GS, Swallow MS, Basques BA, Samuel AM, Ondeck NT et al. Tibial shaft fracture: a large-scale study defining the injured population and associated injuries. Journal of clinical orthopaedics and trauma. 2017;8(3):225-31.

2. Phieffer LS, Goulet JA. Delayed unions of the tibia. Journal of Bone and Joint Surgery-American Volume 2006;(1)206-16.

3. Galbraith JG, O'Leary DP, Dailey HL, Kennedy TE, Mitra A, Harty JA. Preoperative estimation of tibial nail length-Because size does matter. Injury. 2012;43(11):1962-68.

4. Colen RP, Prieskorn DW. Tibial tubercle-medial malleolar distance in determining tibial nail length. Journal of orthopaedic trauma. 2000;14(5):345-8.

5. Venkateswaran B, Warner RM, Hunt N, Shaw DL, Tulwa N, Deacon P. An easy and accurate preoperative method for determining tibial nail lengths. Injury. 2003;34(10):752-5.

6. Blair S. Estimating tibial nail length using forearm referencing. Injury. 2005;36(1):160-2
7. Issac RT, Gopalan H, Abraham M, John C, Issac SM, Jacob D. Preoperative determination of tibial nail length: An anthropometric study. Chinese Journal of Traumatology. 2016;19(3):151-5.

8. Freedman EL, Johnson EE. Radiographic analysis of tibial fracture malalignment following intramedullary nailing. Clinical orthopaedics and related research. 1995; (315)25-33

9. Krettek C, Blauth M, Miclau T, Rudolf J, Könemann B, Schandelmaier P. Accuracy of intramedullary templates in femoral and tibial radiographs. The Journal of bone and joint surgery. British volume. 1996;78(6):963-4.

10. Waldron VD. Predicting intramedullary nail length. American journal of orthopedics (Belle Mead, NJ). 1998;27(5):383

11. Fischmeister MF, Lang T, Reichl $C$, Wechselberger $C$. How to predict requisite nail length in tibial fractures. Archives of orthopaedic and trauma surgery. 1994;113(4):194-5.

12. Hegde A, Mohammed N, Ahmed NR. Correlation between tibial nail length and olecrenon to 5th metacarpal head measurement: An anthropometric study. Chinese Journal of Traumatology. 2019;22(6):361-3. 